ISSN1027-5495. Functional Materials, 24, No.2 (2017), p. 285-289

doi:https://doi.org/10.15407/fm24.02.285

(C) 2017 - STC "Institute for Single Crystals"

\title{
Data processing system of continuous temperature measurement for liquid steel
}

\author{
Xianzhang Feng, Junwei Cheng, Zheng Wang, Yanmei Cui, \\ Yongqiang Wei, Junxing Hou, Zhiqiang Jiang
}

\author{
School of Mechatronics Engineering, Zhengzhou University of Aeronautics, \\ Zhengzhou, Henan, P.R. China, 450015
}

Received December 20,2015

\begin{abstract}
Six different methods of accurate measurement of the temperature of liquid steel in real time are analyzed. . Using a comparison and analysis, a fast and accurate mathematical model is obtained.

Keywords: Liquid steel, temperature measurement, temperature sensor, measurement accuracy, data processing.
\end{abstract}

\begin{abstract}
Проведен анализ шести различных методов точного измерения температуры жидкой стали в реальном времени. С помощью сравнения и анализа результатов получена быстрая и точная математическая модель.
\end{abstract}

Система обробки даних безперервного вимірювання температури рідкої сталі. Сяньчжан Фэн, Чжунвэй Чен, Чжэн Ван, Яньлей Цуй, Юниюн Вэй, Цзюньсін Хоу, Чжіцинь Цзян

Проведено аналіз шести різних методів точного вимірювання температури рідкої сталі в реальному часі. . За допомогою порівняння і аналізу результатів отримана швидка і точна математична модель.

\section{Introduction}

It's very important to improve the production process, improve the quality and reduce the production cost. For Accurate determination of the temperature of liquid metal. In order to improve the quality of casting billet and ensure the stability and uniformity of the steel temperature during continuous casting, the temperature of molten steel should be controlled during the continuous casting process of steel. In the last century of the end of the last century, it is difficult to obtain the realtime temperature curve, but the workers with high strength work, no safe and low accuracy. [1-11]

It is necessary to protect the sensor from the temperature sensor, because the steel has the characteristics of strong corrosion, high erosion, strong thermal shock, etc. Because of the large heat capacity and temperature sensing element, the protective casing has a certain thermal inertia, which is always lagging behind the changes of temperature and temperature, this affects the production efficiency and quality of the continuous casting. $t$ has strong theoretical and practical value to realize accurate and fast measurement of liquid steel temperature of intermediate tank. [12-15]

\section{Principle analysis of data measurement}

Based on the theory of the online black body cavity is a fast and continuous temperature measurement device for steel, as a new type of temperature sensor. Which has the advantages of high accuracy, long service life, the cost of temperature measurement and the actual consumption of platinum and germanium thermo- 
couple plus protective sleeve and fast thermocouple. [16-18]

It plays an important role to improve the billet quality, safe and efficient realization of continuous casting production, optimal control of casting speed and water. It has been widely used in continuous dynamic measurement of liquid steel temperature in continuous casting of intermediate tank. The equations of two dimensional non steady state heat conduction for the sensor can be expressed as

$$
\rho(T) c_{p}(T) \frac{\partial T}{\partial t}=k(T)\left(\frac{\partial^{2} T}{\partial^{2} t}+\frac{1}{r} \frac{\partial T}{\partial r}+\frac{\partial^{2} T}{\partial x^{2}}\right)
$$

Where $k(T)$ is thermal conductivity, $\rho(T)$ is volume quality, $c_{p}(T)$ is specific heat.

When temperature sensor is measured, the part is exposed to air, and a part of the sensor is in the inner part of the steel, and the boundary conditions are different. Ignoring the effect of curvature radius on heat transfer, the partial coefficient of the liquid in the molten steel can be expressed as:

$$
\alpha_{1}=\frac{\lambda}{L} N_{u}=1.06 \frac{\lambda}{L} R_{r}^{.5} P_{r}^{.5}
$$

Where $\lambda$ is the thermal conductivity of molten steel, $L$ is the insertion of a length of the part of molten steel, $N_{u}$ is Nusselt number, $R_{r}$ is Reynolds number, $P_{r}$ is Planck number.

Partial coefficient of air can be expressed as:

$$
\alpha_{2}=0.686 \frac{\lambda}{L}\left(G_{r} P_{r}\right)^{1.4}
$$

\section{Data analysis and processing}

Taking 7 sets of data as the study object, acquisition curves are shown in Figure 1.

Method 1: The output value is corrected on the basis of the arithmetic average value.

For the 1-7 group data, take 10 sampling, the average value, the output value and the error value are shown in Figure 2.

Data linearization is strong in the 3, 7 group from Figure 2, the error is large by the way to deal with the data.

Method 2: The standard error is the error function.

The output value is mean square value by the means of correction. The expression can be expressed as:

$$
\left\{\begin{array}{l}
\sigma_{s}=\sqrt{\sum_{i=1}^{n}\left(x_{i}-\bar{x}\right)^{2} /(n-1)} \\
\bar{\sigma}=\sigma_{s} / \sqrt{n}
\end{array}\right.
$$

The formula used in the measurement can be expressed as:

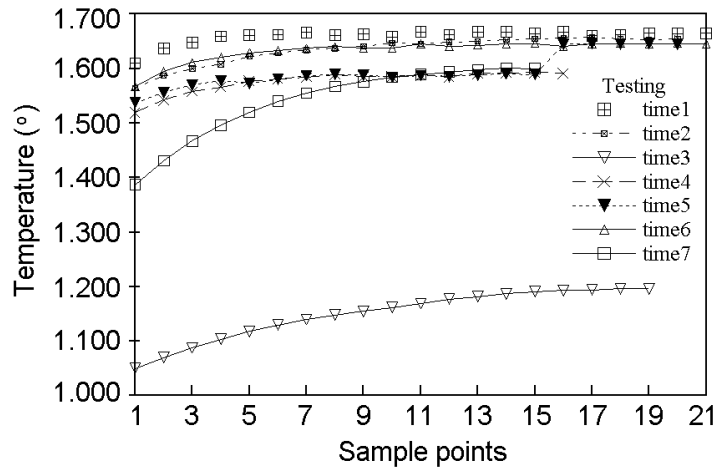

Fig. 1. The curves of acquisition

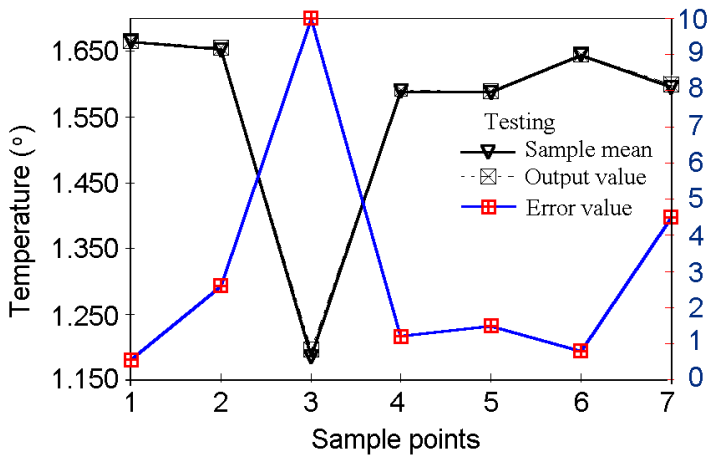

Fig. 2. The curve of the output value and the error value

$$
\left\{\begin{array}{l}
x=\bar{x} \pm \bar{\delta} \\
x=\bar{x} \pm 3 \bar{\delta}
\end{array}\right.
$$

Where $\bar{x}=\frac{1}{n} \sum_{i=1}^{n} x_{i}$ is measured value, $x_{i}$ is measured values, sampling points. $n$ is times of measure the number, $\bar{\delta}$ is the number of sampling.

In the measurement results, the random error of probability is $68.3 \%$ in the range of $-\bar{\delta} \sim+\bar{\delta}$, the random error of probability is $99.7 \%$ in the range of $-3 \bar{\delta} \sim+3 \bar{\delta}, 3 \bar{\delta}$ is he confidence limit, more than the random error is gross error, the measurement results are invalid, this data must to be removed.

Method 3:

From Figure 1 we can see that the error is the biggest for third sets of data and seventh sets of data, and the curve is linear. For the curve No.3, the root mean square error:

$\bar{x}=1147.4$ degrees centigrade, $n=18$

The output value is 1196 degrees centigrade, the measured value and the root mean square error are shown in Figure 3.

The measured value and the root mean square error can be expressed as: 


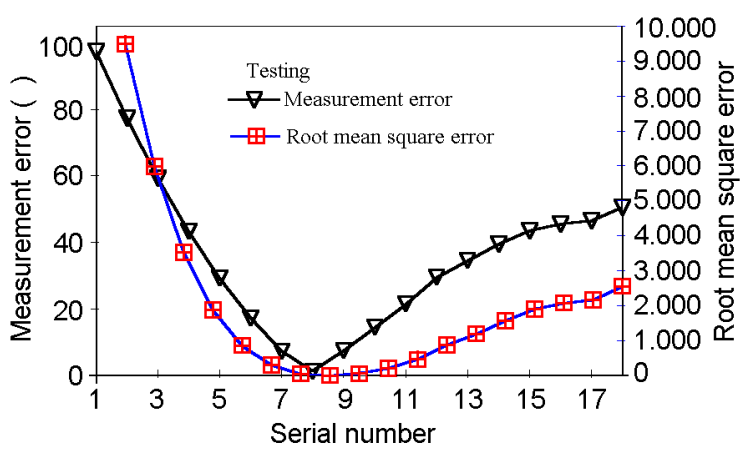

Fig. 3 . The curve of the measured value and the root mean square error $(n=18)$

$$
\left\{\begin{array}{l}
\delta_{s}=\sqrt{\frac{\sum_{1}^{n} \Delta_{i}^{2}}{n-1}}=45.15 \\
\bar{\delta}=\frac{\delta_{s}}{n}=10.73
\end{array}\right.
$$

Calculated output value can be expressed as:

$$
\begin{aligned}
& x=\bar{x}+3 \delta=1179.6 \\
& x=\bar{x}+\delta_{s}=1192.9
\end{aligned}
$$

IF :

\section{Method 4:}

$$
\varepsilon=\frac{\delta_{s}}{\bar{x}}=0.03966
$$

It is needed to fit curves of No.1.

Where $\bar{x}=1536$ degrees centigrade, $n=14$.

The output value is 1600 degrees centigrade, the measured value and the root mean square error are shown in Figure 4.

The error can be expressed as:

$$
\left\{\begin{array}{l}
\delta_{s}=\sqrt{\frac{\sum_{1}^{n} \Delta_{i}^{2}}{n-1}}=66.9 \\
\bar{\delta}=\frac{\delta_{s}}{n}=17.9
\end{array}\right.
$$

Where

$$
x=\bar{x}+3 \delta=1589.7,
$$

The error is larger than the value $1600 \mathrm{de}$ grees centigrade, the introduction of a new correction factor, then:

$$
x=\bar{x}+\delta_{s}=1602.9
$$

IF:

Method 5:

$$
\varepsilon=\frac{\delta_{s}}{\bar{x}}=0.04355
$$

After taking the data of the 10 sampling data, the seventh data were corrected by the

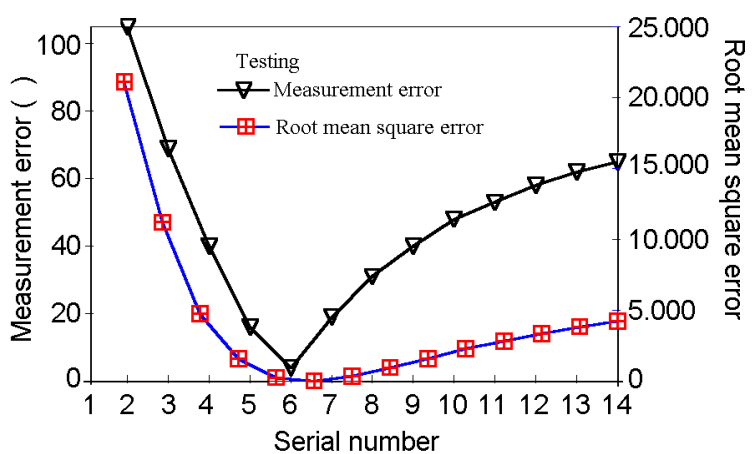

Fig. 4. The curve of the measured value and the root mean square error $(n=14)$

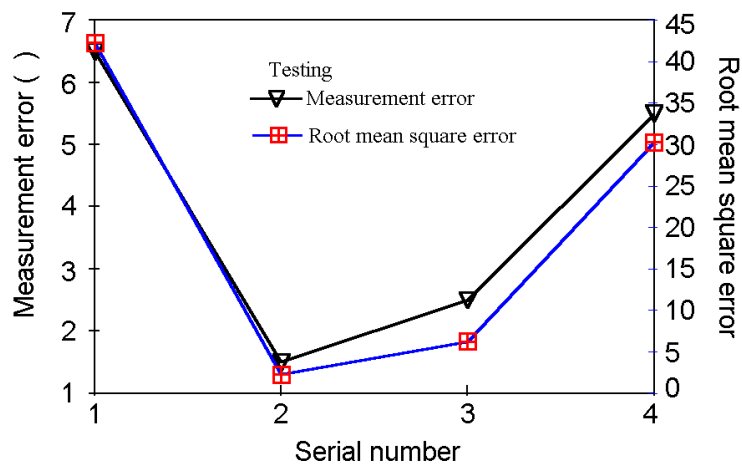

Fig. 5. The curve of the measured value and the root mean square error $(n=4)$

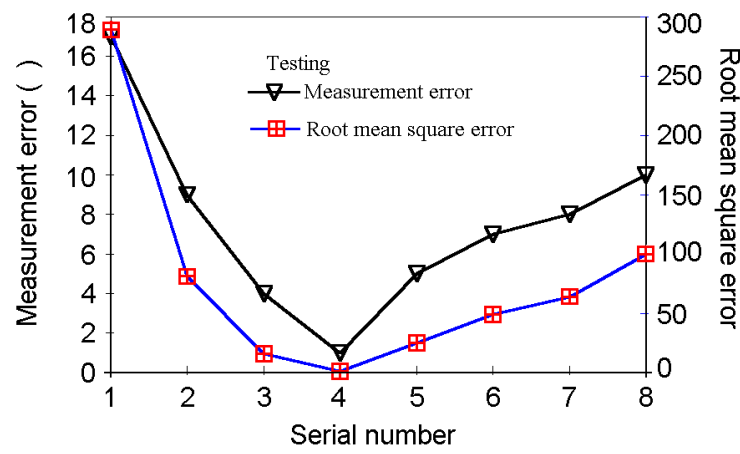

Fig. 6. The curve of the measured value and the root mean square error $(n=8)$

mean square error and the 10 groups of data were corrected.

Where

$\bar{x}=1595.5$ degrees centigrade, $n=4$,

Then

The output value is 1600 degrees centigrade, the measured value and the root mean square error are shown in Figure 5.

The error can be expressed as:

$$
\left\{\begin{array}{l}
\delta_{s}=\sqrt{\frac{\sum_{1}^{n} \Delta_{i}^{2}}{n-1}}=5.2 \\
\bar{\delta}=\frac{\delta_{s}}{n}=2.6
\end{array}\right.
$$




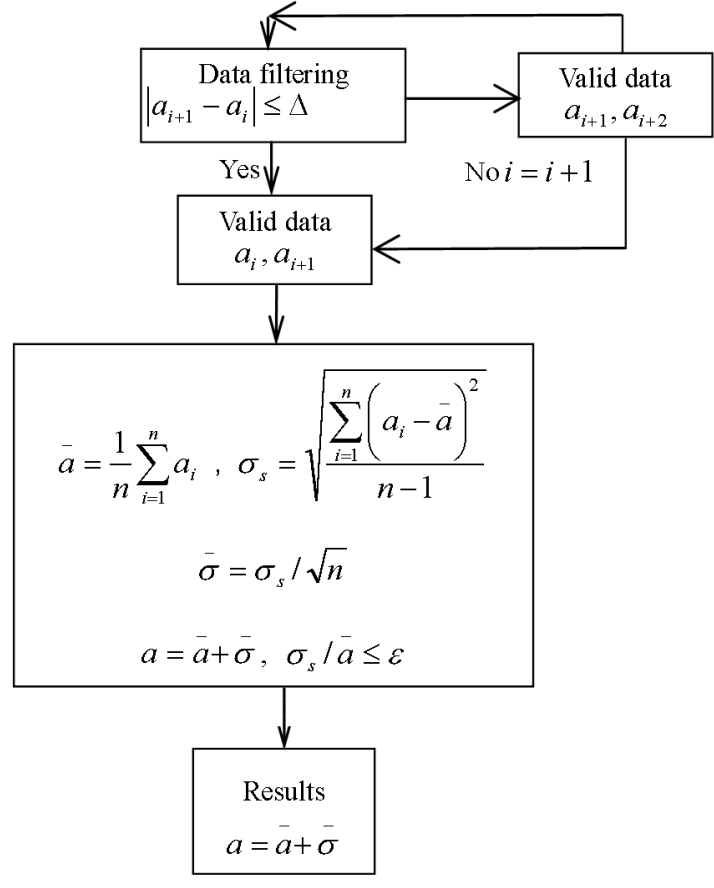

Fig. 7. Data processing of the flow chart

Different criteria, the theoretical output value is:

$$
\left\{\begin{array}{l}
x=\bar{x}+3 \delta=1603.3 \\
x=\bar{x}+\delta=1598.1 \\
x=\bar{x}+\delta_{s}=1600.7
\end{array}\right.
$$

The results show that the accuracy of this method is higher than that of the method 4 .

Method 6:

Analysis of third sets of data, the root mean square error of the tenth time correction:

Where

$$
\bar{x}=1186, n=8 .
$$

Then

The output value is 1196 degrees centigrade, the measured value and the root mean square error are shown in Figure 6.

The error can be expressed as:

$$
\left\{\begin{array}{l}
\delta=\sqrt{\frac{\sum_{1}^{n} \Delta_{i}^{2}}{n-1}}=9.45 \\
\bar{\delta}=\frac{\delta_{s}}{n}=3.34
\end{array}\right.
$$

Based on different criteria, the theoretical output value is:

$$
\left\{\begin{array}{l}
x=\bar{x}+3 \bar{\delta}=1196.02 \\
x=\bar{x}+\bar{\delta}=1189.34 \\
x=\bar{x}+\delta_{s}=1195.45
\end{array}\right.
$$

The results show that the accuracy of this method is higher than that of the method 4 too.

IF

$$
\varepsilon=\frac{\delta_{s}}{\bar{x}}=0.007968
$$

The results show that the accuracy of this method is higher than that of the method 3.

Result:

Based on the results of the verification, given a way of data processing by the use of statistical methods.

1. For a given set of data, the sampling means is directly computed

2. Calculate the value of $\delta_{s}$

3. Set a correction factor $\varepsilon^{*}$, it equals 0.05 , if $\frac{\delta_{s}}{\bar{x}}<\varepsilon^{*}$, Sampling end.

4. Output the display value $\left(x=\bar{x}+\delta_{s}\right)$

\section{Conclusions}

It is closely related to the status of the sensor for the data on-line processing. The time of the temperature sensor is generally shorter, especially the object of measurement of high temperature, to give a transient value in 1-2 seconds, but in the time of each acquisition data, sampling points are more, when the sampling value is gradually reduced, that is, the actual temperature of the liquid steel, at this time should be given a reasonable value, as the sensor sampling data output. According to the time varying curve group, the detection value is generally low to high gradient, and the value of the detection value is stable, but the total experience tends to a gradual value.

\section{Acknowledgements}

This work is supported by the research is supported by Plan For Scientific Innovation Talent of Henan Province(174100510006),“I RTSTHN" (14IRTSTHN003).

\section{References}

1. Wang Y. Construct. Technol. Low Temp., 8, 13, 2011.

2. Feng Xianzhang, Cheng Junwei,Cui Yanmei, Jiang Zhiqiang, Functional Materials, 23(1),132, 2016..

3. Patharkar RG, J. Chem., 5, 1, 2013. 
4. Zhao C, Wang L, Ren J, et al. J NE Univ (Nat Sci) ,12, 1754, 2012.

5. S.C. Bergsma, M.E. Kassner, X.Li et al. J. Mat. Proces. Techn., A254, 112, 1998.

6. J.C. Rocha, B.V. Costa, P.Z .Coura, et al. J. Magn.Magn. Mater. 324, 2342-8, 2012.

7. B.Costner, A.K. Figen, J. Chem, doi:10.1155185957, 2014

8. Sun Haiting, Shi Zhan, Small Type Combustion Eng., 5 , 127, 2008.

9. Research of Distribution of Friction Force and Displacement Field in Hot Strip during Coiling. Iron \& Steel, 3, 16, 2008,

10. B.H. Han, D.G. Sun, J.P. Feng, Coal Sci.Techn. 42(1),76, 2014; .

11. B. Ankamwar, A. Thorat, J. Chem., doi:10.1155831694, 2013.
12. Feng Xianzhang, Cheng Junwei, Cui Yanmei, Jiang Zhiqiang, Functional Materials, 23(4), 636, 2016.

13. Cai LIU, J. Yanshan Univ., 22, 1, 23, 1998

14. Cheng Junwei, Feng Xianzhang, Liu Changhong, Jiang Zhiqiang, J. Plast. Eng., 22(4), 15, 2015 ,

15. Cheng Junwei, Feng Xianzhang, Zhang Xinfang, Jiang Zhiqiang, Forg. Stam. Techn., 40(7), 13, 2015.

16. Zhou Jian, Zhang Tingjie, Zhang Xiaoming et al. Rear Metal Nater. Eng., 33(6), 580, 2004.

17. Zhang Tingjie, Zhang Xiaomin, Tian Feng et al. Rear Metal Nater. Eng., 31(4), 258, 2002,.

18. Z Y Jiang, W P Hu. Mater. Proces. Techn., 102(3): 70, 2000. 